\title{
Erratum to: Exploratory factor analysis for small samples
}

Sunho Jung ${ }^{1} \cdot$ Soonmook Lee ${ }^{2}$

Published online: 12 October 2016

(C) Psychonomic Society, Inc. 2016

Erratum to: Behav Res (2011) 43:701-709

DOI 10.3758/s13428-011-0077-9

The correct affiliation for Sunho Jung is School of Management, Kyung Hee University, Seoul, Korea.

The online version of the original article can be found at http:// dx.doi.org/10.3758/s13428-011-0077-9.

$\triangle$ Sunho Jung

sunho.jung@khu.ac.kr

1 School of Management, Kyung Hee University, Seoul, Korea

2 Department of Psychology, SungKyunKwan University,

Seoul, Korea 